broken line $c c d \mathrm{D}$. If now' the gas is rarefied, the mean length of path of the molecules, and consequently the thickness of each of the layers of uniform temperature, is increased, and the thickness of the stratum across which true conduction takes place is diminished. If, for example, the thicknesses of the layers become $A a^{\prime}$ and $B b^{\prime}$, the thickness of the conducting stratum is reduced to $a^{\prime} b^{\prime}$, and the distribution of temperature is represented by the ordinates of the broken line $C c^{\prime} d^{\prime} D$. The rate of flow of heat in the two cases will be proportional conjointly to the inclination of the line $c d^{\prime}$ or $c^{\prime} d^{\prime \prime}$ to $\mathrm{AB}$, and to the conductivity of the gas; but as the latter factor does not vary with density, the result is proportional to the former only. It is evident that if this view of the matter is approximately correct rarefaction must increase the rate of transmission of heat across a stratum of gas whenever the increased length of path of the molecules, resulting from rarefaction, bears an appreciable proportion to the thickness of the stratum, but that it will have no sensible effect of the kind when the stratum of gas is very thick or the rarefaction itself very small.

I ought to acknowledge that precisely this mode of representing the effect of rarefaction occurred to me only as I was thinking how I could comply with Prof. Osborne Reynolds's wish that I should be "more explicit." When I wrote my last note I had in mind a somewhat different mode of action whereby it seemed that an equivalent result to that here pointed out would be brought about. The further consideration which Prof. Reyrolds's lelter in this week's NATURE has caused me to give to the subject has, however, led me to think that the view given above is not only clearer, but also a nearer approach to a correct representation of the facts than the one I had vreviously adopted. But apart from the accuracy of any particular explanation of hone such a result can occur, the experimental evidence seems to me to prove conclusively that the force in the radiometer does increase (up to a certain point) with rarefaction. The action of convection currents depends to so great an extent on such conditions as the size and shape of the envelope and the position of the fly, and they must be so much disturbed as soon as the vanes begin to move, that if they played the essential part which $I$ understood Prof. Reynolds to attribute to them, I cannot think that the effect of rarefaction would present anything like the degree of regularity that has been actually observed.

November 24

G. CARey Foster

\section{Mr. Crookes and Eva Fay}

THE precise nature and grounds of the attestation given by Mr." Crookes to Eva Fay's "mediumship" appear in an article entitled "Science and Spiritualism" in the Daily Telegraph for March 13, 1875, embodying a communication made by Mr. Crookes himself to the Spiritualist of the preceding day.

The readers of NATURE will be able to judge for themselves by the following extracts from this article, whether Eva Fay was not fully justified in announcing her " meâiumship " to the American putilic as having received Mr. Crookes's "endorsement."

"In the Ssiritualist of yesterday, Mr. William Crookes, F.R.S., prints an account of a séance at his house in which Mrs. Fay exhibited some remarkable phenomena while under severe scientific conditions. The sitting took place on Friday evening, February 19, in the presence of several well-known men of science ; and, on Mr. Crookes's suggestion, the modium was so placed as to form part of an electrical current connected with a galvanometer, indicatiug on a graduated circle the exact defiection produced by the current. In each hand Mrs. Fay held the terminal of a wire, and the fact that she kept continuous hold of the terminals was guaranteed by the amount of deflection of the galvanometer needle, and by the flashes of light which accompany each change of position or break of contact. This method was agreed to by the savants present, as affording absolute certainty that the medium could not remove her hand or body from the wires, whether in a trance or otherwise, without the fact being made known by the galvanometer. The sitting was held in a well-lighted drawing-room, the medium thus "tied down by electricity' being screened by a curtain. What followed is thus clescribed by Mr. Crookes :-

"We commenced the tests at 8.55 P.M.; the deflection by the galvanometer was 2II deg., and the resistance of Mrs. Fay's body 6,600 British Association units. At 8.56 the deflection was $2 I_{4}$ deg, and at this moment a handbell began to ring in the library. At 8.57 the deflection was $2 \times 5$ deg. A hand came out of the cabinet on the side of the door farthest from Mrs. Fay."

A number of other occurrences of the like kind are then recorded; the hand reappearing from time to time, and presenting different members of the party with books and other articles severally appropriate to each, of which Mr. Crookes considered it impossible that Mrs. Fay could herself have gained possession.

He adds :- "Before Mrs. Fay came to the house that evening, she only knew the names of two of the guests who would be present; but during the evening the intelligence at work displayed an unusual amount of knowledge about the sitters and the labours of their lives.'

The entire extract (which I should have reproduced in full if the space of NATURE had permitted) would show that-I. It is true that Mr. Crookes gave his public attestation to the gen uineness of the so-called spiritualistic manifestations which occurred in his house through the "mediumship" of Eva Fay.

2. It is true that Eva Fay went back to the United States armed with Mr. Crookes's public attestation of the genuineness of the performances whirh took place at his house.

3. It is true that Mr. Crookes wrote a letter to a gentleman in the United States, giving a similar attestation, which letter was published in facsimile in an American newspaper.-The only thing that was not true in my statement, was that (through having mislaid the slip containing it) I spoke of this letter as having been addressed to Eva Fay herself, and having been written before her departure.

4. It is true that Eva Fay's public performances in London were imitated at the time by Messrs. Maskelyne and Cooke; and further, that her business agent spontaneously offered Mr. Maskelyne to expose (for a sum of money) the tricks by which she cheated "the F.R.S. people."-If NATURE thinks it worth while to admit into its columns the full particulars of that offer, Mr. Maskelyne is quite ready to furnish them. His general assertion of the fact has been long before the public ("Modern Spiritualism," p. r22), and has remained unchallenged, so far as I am aware, until now.

5. It is true that the whole modus operandi of Eva Fay's public "manifestations" in the United States has been publicly exposed in New York and Boston by Mr. Washington Irving Bishop, as stated in Fraser's Masazine for the present month.

It was not only in entire ignorance of these proceedings, but. under the influence of a report in circulation among the Fellows of the Royal Society-that "Mr. Crookes had given up Spiritualism," that I expressed to Mr. Crookes, on the occasion of his receiving the Royal Medal, my desire to "bury the hatchet." But I most assuredly did not consider myself thereby pledged to keep silence in regard to any further proceedings of the like kind and only learned at the beginning of the present year that Eva Fay had been trading on the "endorsement" given her by "Mr. Crookes and other Fellows of the Royal Society," which she naturally "improved " into that of "the Royal Society of England." November 19 WILLIAM B. CARPENTER

\section{Potential Energy}

WILC you permit me to express a certain amount of scepticism as to the reality of Mr. O'Toole's troubles on this subject? That some statements made in the text-books quoted are not clear-that by an ingenious collocation of isolated passages from different authors some absurd conclusions may be drawn-we admit, but it may be doubted whether a Publius with the keen critical power of Mr. O'Toole would not be able to eliminate these errors or ambiguities by a reference to the context. In support of this position let us take the points raised by $\mathrm{Mr}$. O'Toole in the order adopted by him.

\section{A.-Potential E., as meaning Energy in posse.}

The "doctors". quoted, with one exception, represent potential E. - not as energy in posse, but as kinetic energy in possevery different thing. Just as gold coin-though certainly not money in posse-may correctly be called silver coin (another form of money) in posse.

But it is said this name-and certain phrases employed by the doctors-imply that potential E, is "energy of about-to-supervene motion, or that it does not perform work except through the resulting $\mathrm{E}$. of motion." Mr. O'Toole is so distressed because poor Publius is susceptible to this impression, that I feel some hesitation in asking what is wrong in it? How can work be done without motion? How can the poten. tial E. of a system change without a change in the configuration-i.e., motion of the system? Where is the mistake in the conception of potential E. continuously changing into kinetic energy, and this into work, as suggested by poor "P. M.," who'was so summarily treated by this terrible O'Toole that I quake in my shoes as I think of my fate. 